\title{
Cure monitoring and structural health monitoring of composites using micro-braided distributed optical fibre
}

DOI:

10.1016/j.compstruct.2020.112861

\section{Document Version}

Accepted author manuscript

Link to publication record in Manchester Research Explorer

\section{Citation for published version (APA):}

Rufai, O., Chandarana, N., Gautam, M., Potluri, P., \& Gresil, M. (2020). Cure monitoring and structural health monitoring of composites using micro-braided distributed optical fibre. Composite Structures.

https://doi.org/10.1016/j.compstruct.2020.112861

\section{Published in:}

Composite Structures

\section{Citing this paper}

Please note that where the full-text provided on Manchester Research Explorer is the Author Accepted Manuscript or Proof version this may differ from the final Published version. If citing, it is advised that you check and use the publisher's definitive version.

\section{General rights}

Copyright and moral rights for the publications made accessible in the Research Explorer are retained by the authors and/or other copyright owners and it is a condition of accessing publications that users recognise and abide by the legal requirements associated with these rights.

\section{Takedown policy}

If you believe that this document breaches copyright please refer to the University of Manchester's Takedown Procedures [http://man.ac.uk/04Y6Bo] or contact uml.scholarlycommunications@manchester.ac.uk providing relevant details, so we can investigate your claim.

\section{OPEN ACCESS}




\title{
Cure monitoring and structural health monitoring of composites using micro-braided distributed optical fibre
}

\author{
Olubukola Rufai ${ }^{1}$, Neha Chandarana ${ }^{1}$, Mayank Gautam ${ }^{1}$, Prasad Potluri ${ }^{1}$, Matthieu Gresil ${ }^{2 *}$ \\ ${ }^{1}$ Department of Materials, The University of Manchester, Manchester, UK \\ ${ }^{2} \mathrm{i}$-Composites Lab, Department of Materials Science and Engineering \& Department of Mechanical \\ and Aerospace Engineering, Monash University, Clayton, Australia
}

mailto: Corresponding author: matthieu.gresil@monash.edu

\begin{abstract}
In this paper, cure monitoring of a composite laminate is conducted, followed by subsequent structural health monitoring (SHM). A distributed optical fibre (DOF) sensor was embedded between glass fibre fabric plies during manufacture; part of the DOF length was micro-braided using glass fibres, while the remaining length was left 'bare' (as-received condition). In situ and real-time strain measurement during the infusion and curing processes of the laminate was completed. Cure monitoring of composite materials using different fibre orientations, sensor locations, raw materials, and manufacturing methods has been widely studied. However, no consensus was reached due to differences in raw materials, temperature profile, manufacturing method, fibre orientation, and sensor location. The manufactured composite plate was then subjected to repeated loading during a quasi-static four-point bending test, and the strain development along the length of the DOF was recorded. Comparable results were obtained from the micro-braided and bare sections of the DOF, showing the suitability of micro-braided optical fibres for real-time strain monitoring in composite structures. The micro-braiding DOF facilitates handling for automated manufacturing methods and can be used to follow the full life cycle of a composite from fabrication till end-of-life.
\end{abstract}

Keywords: Cure monitoring; composite materials; distributed optical fibre (DOF); micro-braided optical fibres; residual strain; structural health monitoring (SHM)

\section{Introduction}

Usage of fibre reinforced polymer (FRP) composites has increased over the last three decades in various applications such as aerospace, civil, and automotive industries [1-4]. This increase is due to the advantages composite materials have over their metallic counterparts: high strength-to-weight ratio, good dimensional stability, corrosion resistance, and durability. Glass fibres are the most popular reinforcements for small aircraft, wind turbine blades, boats, vehicle body panels, bumper beams, and sporting goods such as frames of bicycles and tennis rackets, due to their high strength and low density combined with reasonable costs [5]. However, defects can be introduced into these composite structures when manufacturing and can progress to damage during the service life. The growth of such damage can adversely affect the global mechanical performance of the finished part. Non-destructive techniques (NDT) are commonly adopted to detect, localise, and quantify flaws and damage in composites. These include optical and electromagnetic methods [6,7], ultrasonic scanning [8,9], shearography [10,11], acoustic emission [12-14], and thermography [15,16]. Many of these methods are time-consuming to implement and require highly-qualified operators to acquire and analyse the related data. 
Structural health monitoring (SHM) involves the permanent integration of sensors into the host structure for continuous and periodic inspection [17-21]. SHM methods facilitate several levels of damage assessment [22], including the detection and location of damage, classification of damage type, quantification of severity, and prognosis on the remaining life of the structure [1,2,23-25]. Since SHM can provide in situ on-demand assessment, without significant downtime of components, the relative cost can be much lower than conventional NDT.

It is crucial to monitor the composite materials' manufacturing process to identify flaws such as dry regions, delamination, fibre waviness, foreign bodies, voids, and incomplete matrix cure [26-28]. These defects can result in residual stresses or reduced dimensional stability of the manufactured composite. Residual stresses and strains are induced during heating and cooling of the fibres and matrix, potentially affecting the composite product's mechanical properties. Variation in the two constituents' thermal expansion coefficients leads to the matrix compressing the fibres, resulting in residual stresses and strains. The ability to monitor the resin flow during infusion and viscosity during curing serves as a potential method for conducting quality control.

Optical fibre sensors can be used for in situ composite monitoring since embedding them does not interfere significantly with the structure's mechanical properties [29-31]. Insensitivity to electromagnetic interference is another advantage of using optical fibres, compared with other techniques such as dielectric analysis [3,4,32]. Several researchers [25,33-38] studied the residual strain induced in composites during curing using different optical fibre sensors. Strain gauges have been employed for this purpose [39], but the information they provide is local, and many gauges are required to cover a vast sensing region. Global sensing of a structure can be achieved by integrating either distributed or quasi-distributed fibre Bragg grating (FBG) optical fibres [40,41].

A summary of residual strain measurement embedded with different optical fibres in relation to cure monitoring and the residual strain recorded in the longitudinal and transverse direction is presented in Table 1. Sanchez et al. [1,2] embedded a distributed optical fibre close to the top (fifth and sixth plies), middle (third and fourth plies), and bottom (first and second plies) of a carbon fibre/epoxy (CF/Ep) laminate. The highest strain value was recorded at the top with $-405,-347$, and $-291 \mu \varepsilon$ residual strain value from top to bottom of the panel. Huang et al. [33] embedded a pre-tensioned optical fibre longitudinally between the eighth and ninth plies (centre of plies) of a unidirectional CF/Ep preimpregnated fibres (pre-preg) tape. A residual strain of $-1500 \mu \varepsilon$ was recorded due to the thermal contraction of the composite panel. Kang et al. [42] reported various residual strain values depending on the position of the FBG/ Extrinsic Fabry-Perot Interferometric (EFPI) hybrid sensors in the GR/Ep pre-preg. The residual strain recorded by the sensors in the longitudinal and transverse directions to the reinforcing fibres were -140 and $-4000 \mu \varepsilon$, respectively. The higher residual strain was due to the anisotropic behaviour of the unidirectional composite, which causes more thermal and chemical shrinkage in the transverse direction than in the reinforcing fibre direction. Ifju et al. [43] reported a residual strain value of $-5000 \mu \varepsilon$ in the transverse direction and zero in the longitudinal direction of a GR/Ep pre-preg using a thin film of moire interferometry diffraction grating placed between fibres. Leng et al. [44] reported a transverse strain of 4400/4360 and -230/-260 $\mu \varepsilon$ with and without damage respectively, using a EFPI sensor. However, Minakuchi [45] recorded a strain of $-4500 \mu \varepsilon$ using a short tailed FBG embedded through the thickness and in-plane direction of a CF/Ep pre-preg cured in an autoclave.

In summary, various researchers have studied cure monitoring in GF/Ep, CF/Ep, and Gr/Ep composites using different fibre orientations, sensor locations, raw materials, and manufacturing methods. Some agreement was found with the negative and positive residual strain values recorded by the sensors 
oriented longitudinal and transverse to the fibre direction, respectively. However, no consensus was found in the residual strain values, which could be due to the difference in raw materials, temperature profile, manufacturing method, fibre orientation, or sensor location.

Because of their brittleness and ease of breakage, the handling of these optical fibres during composite manufacture can be challenging [46,47]. Micro-braiding was completed to protect the optical fibres and improve their handling and mechanical properties [29].

In the present study, a single distributed optical fibre was embedded during the manufacture of a glass fibre reinforced polymer (GFRP) composite plate. Before embedment, a length of the optical fibre was micro-braided using glass fibres to compare in situ strains monitored by the micro-braided and 'bare' fibre segments. To the author's knowledge, little or no research has been reported on the use of DOF for cure monitoring and SHM of GFRP composites. Micro-braided DOF have not previously been inserted in GFRP composites for full life cycle SHM. The development of strain was monitored during curing of the laminate, and later during mechanical loading of the cured plate.

\section{Distributed optical fibre sensors}

Distributed optical fibre (DOF) sensors have the unique capability of allowing a single length of fibre to be used as multiple, discrete sensing elements for continuous monitoring, making them suitable for strain and temperature measurement in large structures $[1,3,48]$. DOF generally operate either under the principle of optical time domain reflectometry (OTDR) or optical frequency domain reflectometry (OFDR). These methods locate external disturbances by optical characteristics of the various backscatter techniques, including Rayleigh, Raman, and Brillouin scattering [20,41,49,50]. OFDR was selected in this study because of its high spatial resolution of about $10 \mu \mathrm{m}$ compared to OTDR, which has a lower spatial resolution of $0.1 \mathrm{~m}$. OFDR-based systems have a broad dynamic range because of the possibility of coherent detection [51,52]. A swept frequency pulse is used to interact with the optical fibre. In Rayleigh-based OFDR, the sensing fibre measures Rayleigh backscatter, which results from interactions of the transmitted light with imperfections in the silica glass core. The frequency of backscattered light is dependent on its location, enabling localised strain sensing. OFDR allows monitoring structures with spatial resolution of $\mathrm{mm}$ and with strain and temperature resolutions as fine as $1 \mu$ strain or $0.1^{\circ} \mathrm{C}[51,54]$.

The refractive index of a DOF is sensitive to environmental parameters such as temperature, strain, humidity, and pressure. Changes in strain and temperature are the leading cause of spectral shifts in the Rayleigh backscatter profile. Assuming a specific segment $\mathrm{j}$ of fibre is being considered, the reflection spectrum of the unstrained fibre is $\mathrm{U}_{\mathrm{j}}(v)$. When the fibre undergoes external perturbation such as strain or temperature, the segment of the fibre $\mathrm{j}$ will experience a change in reflection spectrum $\Delta \mathrm{u}_{\mathrm{j}}$, which is denoted by $\mathrm{U}_{\mathrm{j}}\left(v-\Delta v_{\mathrm{j}}\right)$. The shift in reflection spectrum $\Delta \mathrm{u}_{\mathrm{j}}$ is calculated by cross-correlating $\mathrm{U}_{\mathrm{j}}(v)$ and $\mathrm{U}_{\mathrm{j}}\left(v-\Delta v_{\mathrm{j}}\right)$. The shift in the spectrum of light scattered in the fibre in response to strain and temperature is comparable to fibre Bragg grating and can be defined by Eq. (1):

$$
\frac{\Delta \lambda}{\lambda}=\frac{\Delta v}{v}=k_{T} \Delta T+k_{\varepsilon} \varepsilon
$$

Knowing that

$$
k_{T}=\alpha+\xi
$$




$$
k_{\varepsilon}=1-\frac{n^{2}}{2}\left(p_{12}-\mu\left(p_{11}+p_{12}\right)\right)
$$

Where $v$ is the mean optical frequency, $\lambda$ is the wavelength, $\alpha$ is the coefficient of thermal expansion (CTE), $\xi$ is the thermo-optic coefficient, $n$ is the refractive index, $\mu$ is Poisson's ratio and $p_{11}, p_{12}$ are component of strain-optic tensor. The values of temperature and strain calibration constants for germanium-doped silica core are $k_{T}\left(6.45 \times 10^{-6}{ }^{\circ} \mathrm{C}^{-1}\right)$ and $k_{\varepsilon}(0.78)$ [55].

The change in temperature $\Delta T$ in the absence of mechanical strain is calculated by Eq. (4):

$$
\Delta T=-\frac{\bar{\lambda}}{c k_{T}} \Delta v
$$

Where c represents the speed of light and $\bar{\lambda}$ the central wavelength, by substituting the constants into the equation, Eq. 4 becomes:

$$
\Delta T=-0.801 \frac{{ }^{\circ} \mathrm{C}}{G H z} \Delta v
$$

$\Delta v$ represents the spectral shift in GHz. The value of -0.801 is specific to the system utilised in the present work: LUNA's ODiSI-B interrogator with a central wavelength of $1550 \mathrm{~nm}$ [55].

The change in mechanical strain $\Delta \varepsilon$ in the absence of temperature is given by Eq. (6)

$$
\Delta \varepsilon=\frac{\bar{\lambda}}{c k_{\varepsilon}} \Delta v
$$

By substituting constants, Eq. 6 becomes:

$$
\Delta \varepsilon=-6.67 \frac{\mu \varepsilon}{G H z} \Delta v
$$

A novel process of implementing micro-braided and bare section of a DOF in a composite laminate for measuring residual strain during curing is investigated. Strain development from both sections of the DOF during cyclic loading under four-point bend was also evaluated. Readings from the micro-braided and bare sections were also compared to determine the effect of micro-braiding on the optical fibre.

\section{Materials and methods}

\subsection{Manufacture of smart composite laminate}

A composite laminate was manufactured from six layers of 2/2 twill-woven E-glass fibre fabric (ply size $=400$ x $200 \mathrm{~mm}$, areal density $=876 \mathrm{~g} / \mathrm{m}^{2}$, supplied by Sigmatex UK Ltd [56]), and an epoxybased resin system, by vacuum-assisted resin infusion moulding (VARIM). The resin system comprised an epoxy and hardener (Araldite LY564 and Aradur 2954, both supplied by Huntsman).

During the lay-up process, a two-metre length, $155 \mu \mathrm{m}$ diameter, single-mode, polyimide-coated, silica glass optical fibre sensor, with low-bend-loss, was embedded between the fourth and fifth fibre plies. Part of the DOF length was micro-braided, to facilitate the handling and improve its strength [29], before the embedding process, while the remaining length was left bare. For more details on the microbraiding process, the reader is referred to [29]. The DOF was carefully inserted and secured beneath 
fibre floats in the fabric to remove the need for a bonding agent. The bare DOF segments were positioned close to the long edge and at the mid-point of the laminate, while the micro-braided optical fibre (MBOF) part was positioned close to the other long edge, as shown in Figure 1. Three strain gauges were also bonded to the surface of the plate. The three OF sensing regions were positioned $50 \mathrm{~mm}$ apart. The ingress point, which is the termination end of the DOF was protected between fibre float while the egress point was protected using a $0.6 \mathrm{~mm}$ diameter polytetrafluoroethylene (PTFE) capillary tube, to prevent breakage of the DOF. The PTFE capillary tube was sealed to avoid resin flow into the tube. An OFDR system was used to monitor strain in the optical fibre during the resin infusion and curing processes. The composite panel was placed in the curing oven with the DOF connected to the LUNA system for data acquisition. Total strain from the LUNA Inc. (ODiSI-B model) interrogator was recorded; temperature and mechanical strain data values were obtained using Eqs. (5) and (7), respectively [55].

\subsection{Mechanical loading experiment}

After manufacture, because of the distance of the DOF to the edges, the composite panel was trimmed to $385 \mathrm{~mm}$ x $150 \mathrm{~mm}$ without touching the egress side. Quasi-static four-point bending was then conducted on an Instron 5969 testing machine equipped with a $50 \mathrm{kN}$ load cell Figure 2. The distance between the loading noses is one half of the support span in accordance with ASTM standard D6272 [57]. Aluminium spreader bars were placed between the test machine and specimen to ensure uniform load distribution across the panel width. During the test, a crosshead speed of $1 \mathrm{~mm} / \mathrm{min}$ was maintained. Loading was completed in a series of loading/unloading cycles to determine the repeatability associated with strain measurement in the bare and micro-braided OF segments. During each loading cycle, the surface strain was measured using uniaxial electrical strain gauges positioned on the surface of the laminate, in the centre of each DOF sensing region. Table 2 shows the average strain measured by the strain gauges. The DOF's acquisition rate is $5 \mathrm{~Hz}$ with gage length of $1.25 \mathrm{~mm}$ using an OFDR-bases interrogator (ODiSI-B system, supplied by LUNA Inc.).

Visible damage was not observed until the specimen reached strain levels of 10000-11000 $\mu \varepsilon$, during repeated loading from cycle 12 onwards. When the specimen was subjected to repeated loading with the same maximum strain value, a loss in stiffness was observed from the reduction in the maximum stress value at each loading cycle.

\section{Results and discussion}

\subsection{Strain monitoring during curing}

The curing cycle used during the GFRP composite manufacture is shown in Figure 3, with temperature and total strain curves for the different DOF sections displayed. The cure cycle is divided into five temporal stages:

I. $\quad$ Increase from room temperature to $80^{\circ} \mathrm{C}$ in 1 hour;

II. Temperature dwell at $80^{\circ} \mathrm{C}$ for 1 hour;

III. Temperature increase from $80^{\circ} \mathrm{C}$ to $160^{\circ} \mathrm{C}$ in 1 hour;

IV. Dwell at $160^{\circ} \mathrm{C}$ for 2 hours;

V. The composite was allowed to cool to room temperature in the oven. 
The composite panel experienced several temperature changes, which led to local strain and stress development. The thermal strain was measured by the un-bonded part of the DOF, protected with the PTFE capillary tube. The strain recorded by bare and micro-braided OF sections is comparable, indicating that the MBOF is suitable for strain measurement in the composite structure. To fully understand what is happening during curing, the mechanical strain needs to be analysed in isolation from the thermal strain.

he mechanical strain induced in the composite resulting from curing is derived from the total strain and thermal strain given by Eq. (8):

$$
\varepsilon_{T}=\varepsilon_{m}+\varepsilon_{t}
$$

Where $\varepsilon_{T}$ is the total strain, $\varepsilon_{m}$ is the mechanical strain, and $\varepsilon_{t}$ is the thermal strain.

The mechanical strain and temperature curve during the curing of the composite panel are presented in Figure 4. Interpretation of the measurements enables ease of identifying and controlling every step of the cure cycle. The following steps below explain what is happening at each stage of the cure cycle:

I. As the resin's viscosity decreases due to an increase in temperature, the distribution of resin was experienced, which caused the compression of the resin on the DOF leading to the compressive strain (negative strain) recorded.

II. Change in strain was observed (positive strain) during the dwell period, which could be due to the matrix's thermal expansion caused by changes in the adhesive condition between the resin and the optical fibre. At this stage, the resin's viscosity is increased, causing a reduction in the flow of resin known as the gel point $[25,58]$.

III. A positive strain is observed, possibly due to the increase in temperature on material's thermal expansion. This is followed by a reduction in the positive strain, which could be due to resin shrinkage associated with polymerisation [25,58].

IV. At the post-cure cycle, a near-constant strain level was observed, because most of the polymerisation reaction has occurred during the curing cycle.

V. During the cooling stage, the DOF detects an increase in compressive strain (negative strain) due to the thermal shrinkage of the epoxy resin [44].

In all DOF regions, compressive strain developed in a short period during cooling, as shown in Figure 4. The average residual strain observed in the bare DOF close to the panel edge was $-254 \mu \varepsilon$, while the change in compressive strain from the beginning to the end of the cooling stage was $-932 \mu \varepsilon$. The average strains observed in the mid-line of the panel were higher: $-310 \mu \varepsilon$ and $-1028 \mu \varepsilon$, respectively. Compressive strain was observed in both sections of the bare DOF, because, during cooling, the panel is already cured and strain is induced due to thermal contraction of the matrix [42].

The green curve in Figure 4 shows the strain profile of the MBOF located at the other edge of the panel. The average residual stain observed was $-411 \mu \varepsilon$, while the change in strain due to cooling was $1063 \mu \varepsilon$. The MBOF recorded the highest residual strain as temperature decreases compared to the bare DOF's. The $47 \%$ difference in the residual strain of the bare DOF edge and the MBOF edge could be due to the increase in diameter of the MBOF $(\sim 470 \mu \mathrm{m})$. The larger diameter introduces resin pockets around the MBOF, as detailed in the authors' previous work [29]. Consequently, this results in more 
significant compressive strains being recorded when the resin undergoes thermal shrinkage during cooling.

The residual strain and the percentage difference between the bare and MBOF sections, which were both $24 \mathrm{~cm}$ long are shown in Figure 5. The bare edge and the MBOF edge recorded different strain values, likely due to the differences in diameter, which are 155 and $470 \mu \mathrm{m}$ respectively, and the formation of a resin pocket around the MBOF as reported in the previous publication [29].

To further understand the differences in strain recorded by each DOF section, the three sections were divided into sub-sections, $9 \mathrm{~cm}$ apart. Figure 6 shows the mechanical strain evolution during curing in each of the DOF sub-sections. Table 3 shows the average negative strain recorded during cooling for all sections and sub-section of the DOF. Sub-section 3 recorded the highest strain value in all cases. However, all the sections and sub-section of the DOF strain value falls within the range of uncertainty.

\subsection{Strain monitoring during four-point bending}

The durability of the MBOF was estimated by comparing strain measurement with bare DOF when the composite panel was subjected to four-point bending. Figure 7 shows the strain development recorded by the sections of DOF and surface-mounted strain gauges during the $11^{\text {th }}$ and $14^{\text {th }}$ cycles of loading. All sections of the DOF recorded compressive strain because of their position in the composite, which lies between the fourth and fifth layer and loaded in compression. However, the DOF recorded lower strain compared to the strain gauge located at the top of the panel. Figure 8 shows the development of strain during the final loading cycle 26. Similar strain histories were observed between the different sections, except for the dropout in the strain values.

It is observed that has the bending force increased in cycle 26; a spike in strain value of the sections of the DOF appeared, which could be due to the strain gradient in the composite caused when the strain exceeds $517 \mu \varepsilon$ for a $1.25 \mathrm{~mm}$ gage [59]. The strain profile along the sections of the DOF for cycle 11, 14, and 26 is presented in Figure 9. Due to the loading and unloading associated with each cycle, the strain data recorded by the DOF sections returned to the initial starting point. The location of the peak remained the same in successive loading cycles. The peak in cycle 11 could be an indication of microcrack initiation in the composite panel. Barrias et al. [60] reported a peak in strain in a crack's vicinity, which progressed as loading increased in reinforced concrete. The increase in strain peak evolved in all sections of the DOF, and this could be due to local interaction with fibres or delamination. Delamination was suspected due to the emergence of whitening in the panel as loading progressed (this is possible because the panel is a GFRP). The increase in peak strain was consistent for the three sections of the DOF. Researchers [61,62] have reported a sudden spike in strain values as a result of improper bonding of the sensor to the host surface or local interaction with adjacent fibres.

The photographic and c-scan images of the laminate are shown in Figure 10. The location of the peak for the sections of the DOF is marked out on the specimen, which correlates with the location of the whitening observed on the laminate due to delamination. The result shows a good indication that all the DOF sections, both bare and MBOF, were sensitive to the initiation and growth of damage in the laminate. 


\section{Concluding remarks}

An experimental investigation into real-time cure monitoring of a composite laminate using an embedded DOF sensor has been conducted. When a part of the optical fibre is micro-braided, the integrity of the strain measurement was studied and compared against strain measurements obtained with the bare (as received) DOF. It was possible to follow the full curing process of the laminate. Isolation of mechanical strain allowed us to interpret the strain reading as temperature changes at every stage of curing, which was impossible with total strain. During the cooling stage, compressive strain was recorded by the DOF due to stress relief of the low viscosity resin. Different residual strain measurements by the bare edge and MBOF edge could be due to differences in the diameter of the bare and MBOF. It was consequently causing an increase in resin pocket around the MBOF, resulting in higher compressive strain. It was also observed that when the sections of the DOF was divided into subsections, sub-section two closer to the middle recorded the lowest residual strain, this was suggested to be due to the DOF sections experiencing complete axial strain. The repeated loading cycle of the fourpoint bending test showed that both the bare and micro-braided section of the DOF embedded during manufacture could perform structural health monitoring of the composite panel. Through the experiments performed, we can provide a basis for efficient smart processing of composite with MBOF, which shows good strain measurement sensitivity. Future research will be on integrating the MBOF during braiding or weaving of preforms for strain measurement.

\section{Acknowledgements}

The researchers are greatly appreciative of the Schlumberger Foundation's financial support, which made the completion of this project possible.

\section{Authors Statement}

OR and MG developed the experiment's concept; OR, NC, and MG performed the experiments. OR, NC, and MG analysed the data; OR, NC, and MG wrote the paper; NC, PP, and MG reviewed the paper.

\section{References}

1. Sánchez, D.M.; Gresil, M.; Soutis, C., "Distributed internal strain measurement during composite manufacturing using optical fibre sensors", Compos. Sci. Technol. 2015, 120, 49-57.

2. Chandarana, N.; Sanchez, D.; Soutis, C.; Gresil, M., "Early Damage Detection in Composites during Fabrication and Mechanical Testing", Materials (Basel). 2017, 10, 1-16.

3. Barrias, A.; Casas, J.R.; Villalba, S., "A Review of Distributed Optical Fiber Sensors for Civil Engineering Applications", Sensors. 2016, 16, 1-35.

4. $\quad$ Kuang, K.S.C.; Cantwell, W.. J.; Scully, P.J., "An evaluation of a novel plastic optical fibre sensor for axial strain and bend measurements", Meas. Sci. Technol. 2002, 13, 1523-1534.

5. $\quad$ Chawla, K.K., "Glass Fibres", Encycl. Mater. Sci. Technol. (Second Ed. 2001, 3541-3545.

6. $\quad$ Yang, S.-H.; Kim, K.-B.; Oh, H.G.; Kang, J.-S., "Non-contact detection of impact damage in CFRP composites using millimeter-wave reflection and considering carbon fiber direction", NDT\&E Int. 2013, 57, 45-51. 
7. Koyama, K.; Hoshikawa, H.; Kojima, G., "Eddy Current Nondestructive Testing for Carbon Fibre-Reinforced Composites", J. Press. Vessel Technol. 2013, 135, 1-5.

8. Katunin, A.; Dragan, K.; Dziendzikowski, M., "Damage identification in aircraft composite structures: A case study using various non-destructive testing techniques", Compos. Struct. 2015, 127, 1-9.

9. Gholizadeh, S., "A review of non-destructive testing methods of composite materials", Struct. Intergrity Procedia. 2016, 1, 050-057.

10. Hung, Y.Y.; Yang, L.X.; Huang, Y.H., Non-destructive evaluation (NDE) of composites: digital shearography, in: Non-Destructive Eval. Polym. Matrix Compos., Woodhead Publishing Limited, 2013: pp. 84-115. doi:10.1533/9780857093554.1.84.

11. Toh, S.L.; Chau, F.S.; Shim, V.P.W.; Tay, C.J.; Shang, H.M., "Application of Shearography in Nondestructive testing of Composite plates", J. Mater. Process. Technol. 1990, 23, 267-275.

12. Sarasini, F.; Santulli, C., Non-destructive testing (NDT) of natural fibre composites: acoustic emission technique, in: Nat. Fibre Compos., 2014: pp. 273-302.

13. Gholizadeh, S.; Leman, Z.; Baharudin, B.T.H.T., "A review of the application of acoustic emission technique in engineering", Struct. Eng. Mech. 2015, 54, 1075-1095.

14. Gresil, M.; Saleh, M.N.; Soutis, C., "Transverse Crack Detection in 3D Angle Interlock Glass Fibre Composites Using Acoustic Emission", Materials (Basel). 2016, 9, 1-20.

15. Yang, S.; Tian, G.Y.; Abidin, I.Z.; Wilson, J., "Simulation of edge cracks using pulsed Eddy current stimulated thermography", J. Dyn. Syst. Meas. Control. 2011, 133,.

16. Ciampa, F.; Mahmoodi, P.; Pinto, F.; Meo, M., "Recent advances in active infrared thermography for non-destructive testing of aerospace components", Sensors. 2018, 18, 1-37.

17. Gresil, M.; Poohsai, A.; Chandarana, N., "Guided wave propagation and damage detection in composite pipes using piezoelectric sensors", Procedia Eng. 2017, 188, 148-155. doi:10.1016/j.proeng.2017.04.468.

18. Qing, X.; Kumar, A.; Zhang, C.; Gonzalez, I.F.; Guo, G.; Chang, F.-K., "A hybrid piezoelectric/fibre optic diagnostic system for structural health monitoring", Smart Mater. Struct. 2005, 14, 98-103.

19. Giurgiutiu, V., Structural health monitoring with piezoelectric wafer active sensors, 2014.

20. Güemes, A.; Fernández-López; Soller, B., "Optical fiber distributed sensing - physical principles and applications", Struct. Heal. Monit. 2010, 9, 233-245. doi:10.1177/1475921710365263.

21. Lau, K.; Chan, C.; Zhou, L.; Jin, W., "Strain monitoring in composite-strengthened concrete structures using optical fibre sensors", Compos. Part B. 2001, 32, 33-45.

22. Worden, K.; Dulieu-Barton, J.M., "An overview of intelligent fault detection in systems and structures", Struct. Heal. Monit. 2004, 3, 85-98.

23. Muller, A.; Soutis, C.; Gresil, M., "Image reconstruction and characterisation of defects in a carbon fibre/epoxy composite monitored with guided waves", Smart Mater. Struct. 2019, 28, 121.

24. Philibert, M.; Soutis, C.; Gresil, M.; Yao, K., "Damage Detection in a Composite T-Joint Using Guided Lamb Waves", Aerospace. 2018, 5, 1-13.

25. Poggetti, I.; Dyson, J.; Sanchez, D.M.; Albertini, G.; Soutis, C.; Gresil, M.; Corinaldesi, V., "Distributed internal strain measurement of the fluid-solid state coefficients of thermal 
expansion below the glass transition temperature during a composite manufacturing process", $J$. Compos. Mater. 2018, 52, 3053-3084.

26. Hou, W.; Zhang, W., Advanced Composite Materials Defects/Damages and Health Monitoring, in: 2012 Progn. Syst. Heal. Manag. Conf., Beijing, 2012: pp. 1-5. doi:10.1109/PHM.2012.6228804.

27. Greenhalgh, E.S., Defects and damage and their role in the failure of polymer composites, in: Fail. Anal. Fractography Polym. Compos., 2009: pp. 356-440.

28. Khoun, L.; Oliveira, R. de; Michaud, V.; Hubert, P., "Investigation of process-induced strains development by fibre Bragg gratingsensors in resin transfer moulded composites", Compos. Part A. 2011, 42, 274-282.

29. Rufai, O.; Gautam, M.; Potluri, P.; Gresil, M., "Optimisation of optical fibre using microbraiding for structural health monitoring", J. Intell. Mater. Syst. Struct. 2019, 30, 171-185.

30. Pan, X.; Liang, D.; Li, D., "Optical fiber sensor layer embedded in smart composite material and structure", Smart Mater. Struct. 2006, 15, 1231-1234.

31. Hamouda, T.; Seyam, A.-F.; Peters, K., "Evaluation of the integrity of 3D orthogonal woven composites with embedded polymer optical fibers", Compos. Part B. 2015, 78, 79-85.

32. Meng, L.; Wang, L.; Hou, Y.; Yan, G., "A research on low modulus distributed fiber optical sensor for pavement material strain monitoring", Sensors. 2017, 17, 1-13.

33. Huang, C.; Zeng, X.; Arcand, A.; Lee-Sullivan, P., "Simultaneous temperature and strain monitoring of composite cure using a Brillouin-Scattering-Based distributed fiber optic sensor", Smart Struct. Mater. 2001, 4328, 70-78.

34. Woerdeman, D.L.; Spoerre, J.K.; Flynn, K.M.; Parnas, R.S., "Cure monitoring of liquid composite molding process using fibre optics sensors", Polym. Compos. 1997, 18, 133-150.

35. He, Y.; Li, Y.; Li, N.; Hao, X., "Online monitoring method of degree of cure during nonisothermal microwave curing process", Mater. Res. Express. 2018, 5, 1-10.

36. Sampath, U.; Kim, D.; Kim, H.; Song, M., "Fiber-optic miniature sensor for in situ temperature monitoring of curing composite material", J. Mordern Opt. 2018, 65, 781-787.

37. Lekakou, C.; Cook, S.; Deng, Y.; Ang, T.W.; Reed, G.T., "Optical fibre sensor for monitoring flow and resin curingin composites manufacturing", Compos. Part A. 2006, 37, 934-938.

38. Lammens, N.; Kinet, D.; Chah, K.; Luyckx, G.; Caucheteur, C.; Degrieck, J.; Mégret, P., "Residual strain monitoring of out-of-autoclave cured parts by useof polarization dependent loss measurements in embedded optical fiber Bragg gratings", Compos. Part A. 2013, 52, 38-44.

39. Crasto, S.A.; Kim, R.Y., "In Situ Monitoring of Residual Strain Development During Composite Cure", Polym. Compos. 2002, 23, 454-463.

40. Kher, S.; Saxena, M.K., Distributed, advanced fibre optic sensors, in: Appl. Opt. Fibers Sens., 2019: pp. 1-25.

41. Glisic, B., Distributed fiber optic sensing technologies and applications-an overview, 2013.

42. Kang, H.-K.; Kang, D.-H.; Bang, H.-J.; Hong, C.-S.; Kim, C.-G., "Cure monitoring of composite laminates using fiber optic sensors", Smart Mater. Struct. 2002, 11, 279-287.

43. Ifju, P.G.; Niu, X.; Kilday, B.C.; Liu, S.C.; Ettinger, S.M., "Residual strain measurement in composites using the cure-referencing method", Exp. Mech. 2000, 40, 22-30.

44. Leng, J.S.; Asundi, A., "Real-time cure monitoring of smart composite materials using extrinsic Fabry-Perot interferometer and fiber Bragg grating sensors", Smart Mater. Struct. 2002, 11, 
249-255.

45. Minakuchi, S., "In situ characterization of direction-dependent cure-induced shrinkage in thermoset composite laminates with fiber-optic sensors embedded in through-thickness and inplane directions", J. Compos. Mater. 2015, 49, 1021-1034.

46. Glaesemann, G.S., Advancements in mechanical strength and reliability of optical fibres, in: Reliab. Opt. Fibre Opt. Fibre Syst., Boston, Massachusetts, 1999: pp. 1-23.

47. Grave, J.H.L.; Håheim, M.L.; Echtermeyer, A.T., "Measuring changing strainfields in composites with Distributed Fiber-Optic Sensing using the optical backscatter reflectometer", Compos. Part B. 2015, 74, 138-146.

48. Güemes, A.; Fernández-López, A.; Fernandez, P., Damage Detection in Composite Structures from Fibre Optic Distributed Strain Measurements, in: 7th Eur. Work. Struct. Heal. Monit., Nantes, 2014: pp. 528-535.

49. Bos, J.; Klein, J.; Froggatt, M.; Sanborn, E.; Gifford, D., Fiber optic strain, temperature and shape sensing via OFDR for ground, air and space applications, in: Nanophotonics Macrophotonics Sp. Environ. VII, San Diego, California, 2013: pp. 1-15. doi:10.1117/12.2025711.

50. Vaezi-Nejad, S.M., Selected topics in advanced solid state and fibre optic sensors, 2000.

51. Ding, Z.; Wang, C.; Liu, K.; Jiang, J.; Yang, D.; Pan, G.; Pu, Z.; Liu, T., "Distributed optical fiber sensors based on optical frequency domain reflectometry: A review", Sensors. 2018, 18, $1-31$.

52. Bergman, A.; Davidi, R.; Shalev, I.A.; Ovadia, L.; Langer, T.; Tur, M., "Increasing the measurement dynamic range of rayleigh-Based OFDR interrogator using an amplifying add-on module", IEEE Photonics Technol. Lett. 2016, 28, 2621-2624.

53. Tsai, J-T., Dustin, J.S., Mansson, J-A., "Cure strain monitoring in composite laminates with distributed optical sensor., Composites Part A 125 (2109).

54. Samiec, D., "Distributed fibre-optic temperature and strain measurement with extremely high spatial resolution", Opt. Metrol. 2012.

55. LUNA, ODiSI-B Optical Distributed Sensor Interrogator, 2013.

56. Sigmatex UK Ltd, Unit G, Royle Pennine trading Est., Lynroyle way, Rochdale OL11 3EX, n.d.

57. ASTM Standard D6272, Standard test method for flexural properties of unreinforced and reinforced plastics and electrical insulating materials by four-point bending, 2017. doi:10.1520/D6272-17E01.

58. Ferdinand, P.; Magne, S.; Dewynter-Marty, V.; Rougeault, S.; Maurin, L., "Applications of Fiber Bragg Grating sensors in the composite industry", MRS Bull. 2002, 27, 400-407.

59. LUNA, User's Guide / ODiSI-B, 2007.

60. Barrias, A.; Casas, R.J.; Villalba, S., "Embedded distributed optical fiber sensors in reinforced concrete structures-A case study", Sensors. 2018, 18, 1-22.

61. Błażejewski, W.; Gąsior, P.; Kaleta, J., Application of optical fibre sensors to measuring the mechanical properties of composite materials and structures, in: Adv. Compos. Mater. Ecodesign Anal., 2011: pp. 221-246.

62. $\quad$ Lawrence, C.M.; Nelson, D.V.; Spingarn, J.R.; Bennett, T.E., Measurement of process-induced strains in composite materials using embedded fiber optic sensors, in: Smart Struct. Mater. 1996, San Diego, CA, 1996: pp. 60-68. 


\section{List of figures}


Figure 1: Schematic representation of the composite plate (with DOFS embedded between the fourth and fifth fabric layers, shown in orange).

Figure 2: $\quad$ Four-point bending experimental set up: (a) before loading, (b) during loading.

Figure 3: Temperature measured by distributed optical fibre sensor (black) and total strain measured by DOF in different sections of the optical fibre: bare optical fibre at the edge (blue), bare optical fibre at the middle (red), and micro-braided optical fibre (MBOF) at the edge (green).

Figure 4: $\quad$ Mechanical strain profile for bare optical fibre at the edge of the panel (blue), bare optical fibre at the middle of the panel (red), and micro-braided optical fibre (MBOF) at the edge of the panel (green).

Figure 5: $\quad$ Percentage difference in measured residual strain in different DOF sections: bare edge (green), bare middle (red), MBOF edge (black).

Figure 6: Mechanical strain for sub-sections: 1 (red), 2 (blue), and 3 (green) of each DOF section: (a) bare edge, (b) bare middle, and (c) micro-braided optical fibre (MBOF) edge.

Figure 7: $\quad$ Strain development from four-point bend test by surface mounted strain gauge and sections of the distributed optical fibre during (a) $11^{\text {th }}$ cycle and (b) $14^{\text {th }}$ cycle (c) enlarged image of cycle 11 and (d) enlarged image of cycle 14 showing little spikes.

Figure 8: (a) Strain development from 4 point bend test by surface mounted strain gauge and distributed optical fibre during the $26^{\text {th }}$ cycle, (b) enlarged image.

Figure 9: $\quad$ Strain profile of cycle 11 (black) at maximum load of $2766 \mathrm{~N}$, cycle 14 (red) at maximum load of $4375 \mathrm{~N}$, and cycle 26 (blue) at maximum load of $3293 \mathrm{~N}$.

Figure 10: Whitening in the laminate might be due to defect growth (a) photograph (b) ultrasonic cscan. 


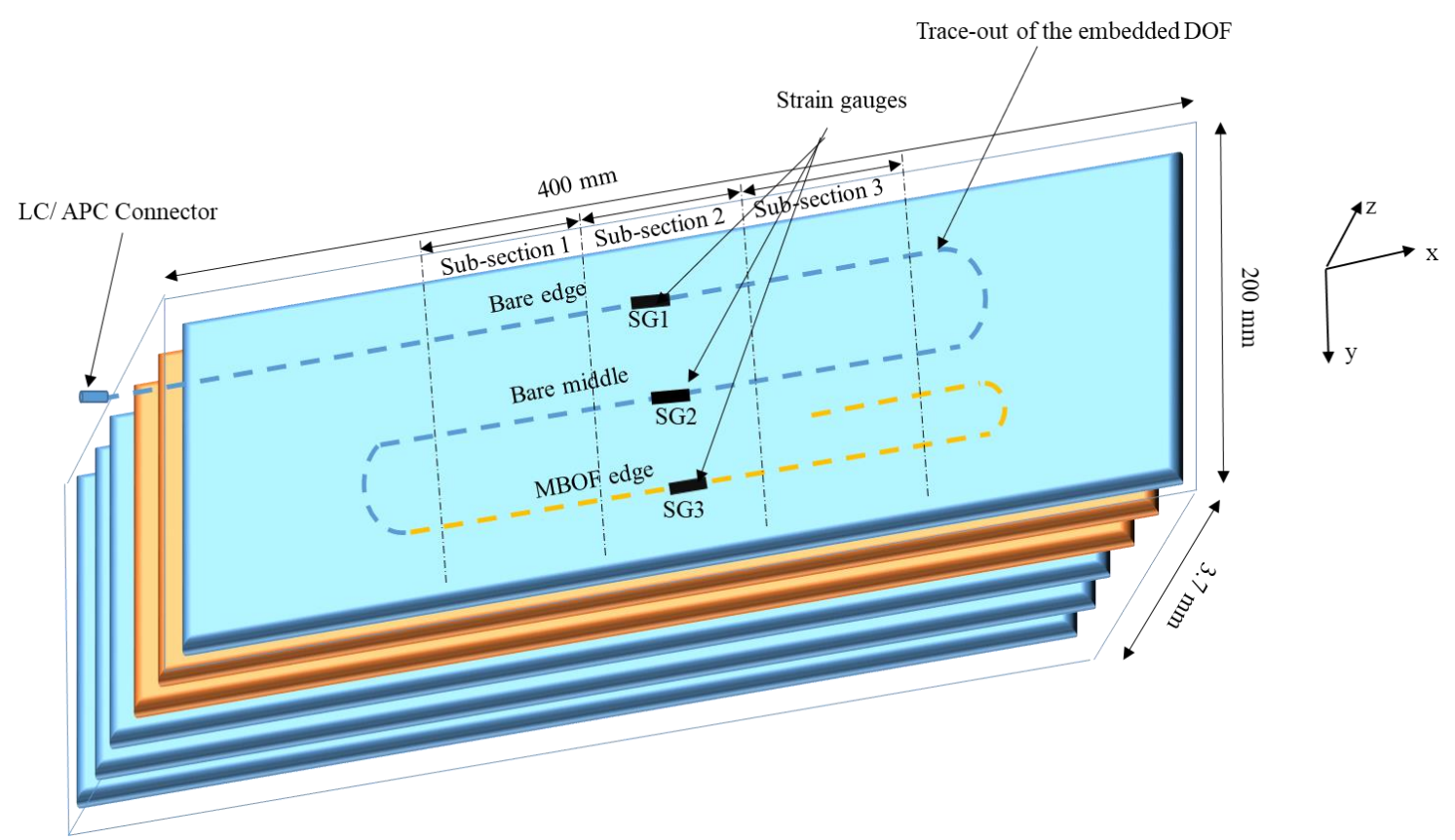

Figure 1 


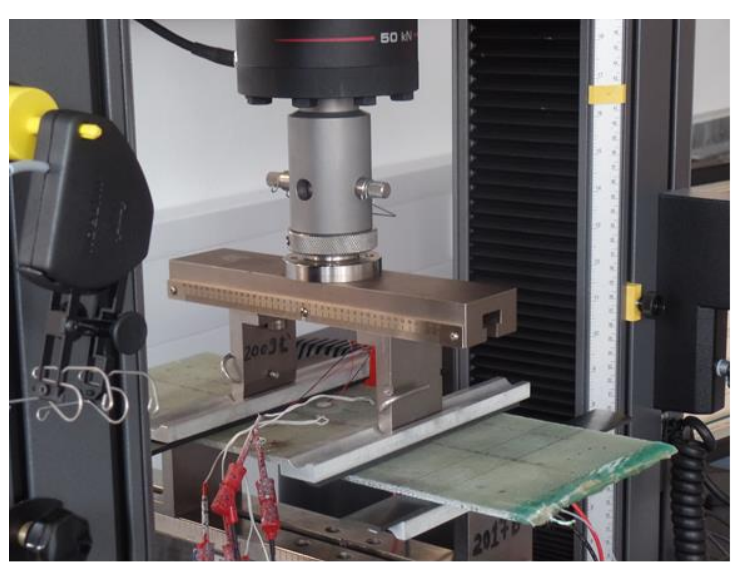

(a)

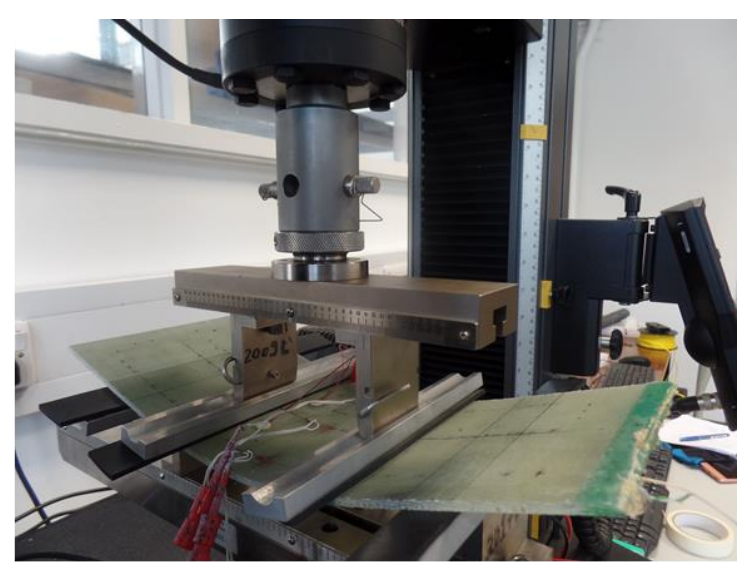

(b)

Figure 2 


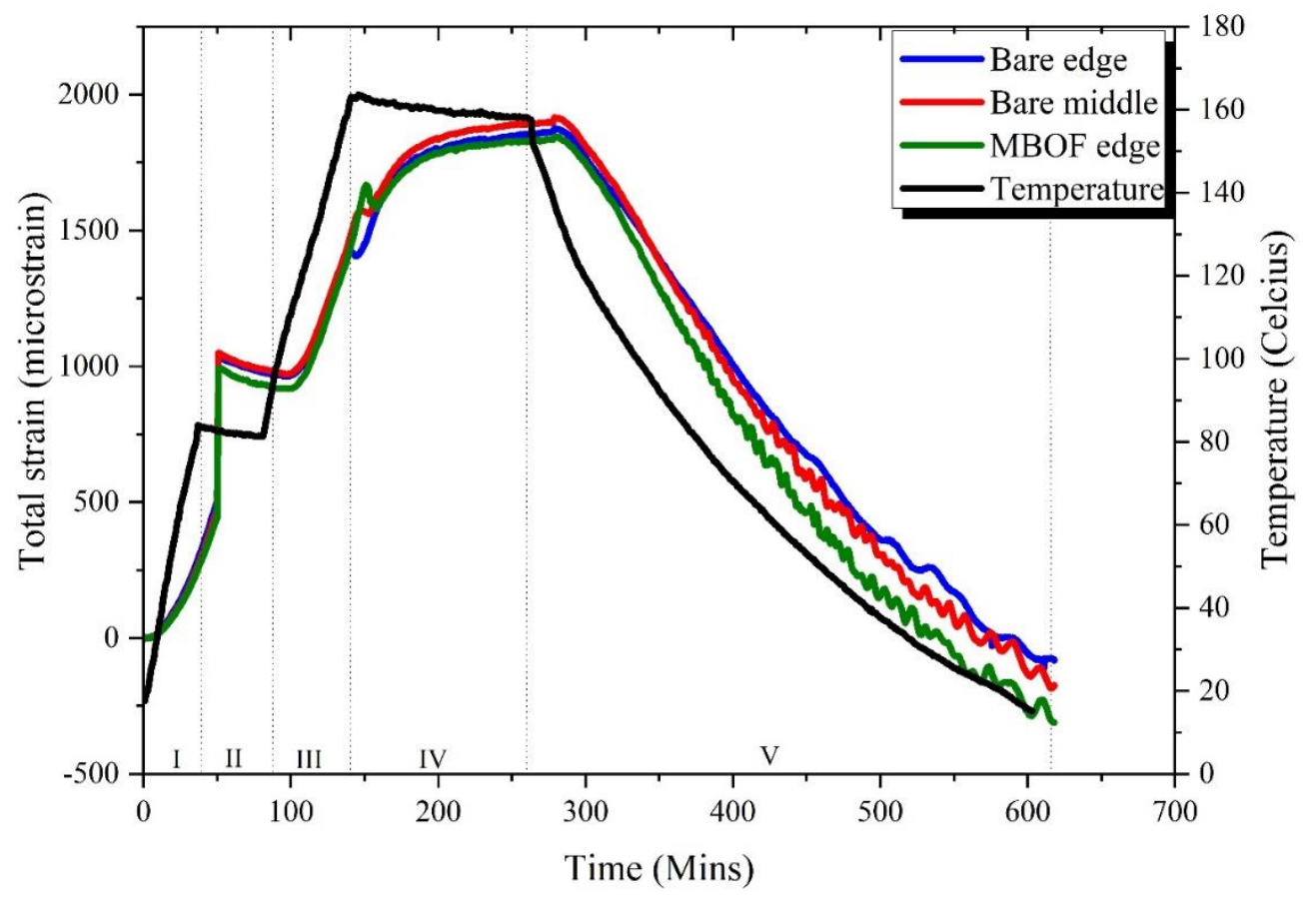

Figure 3 


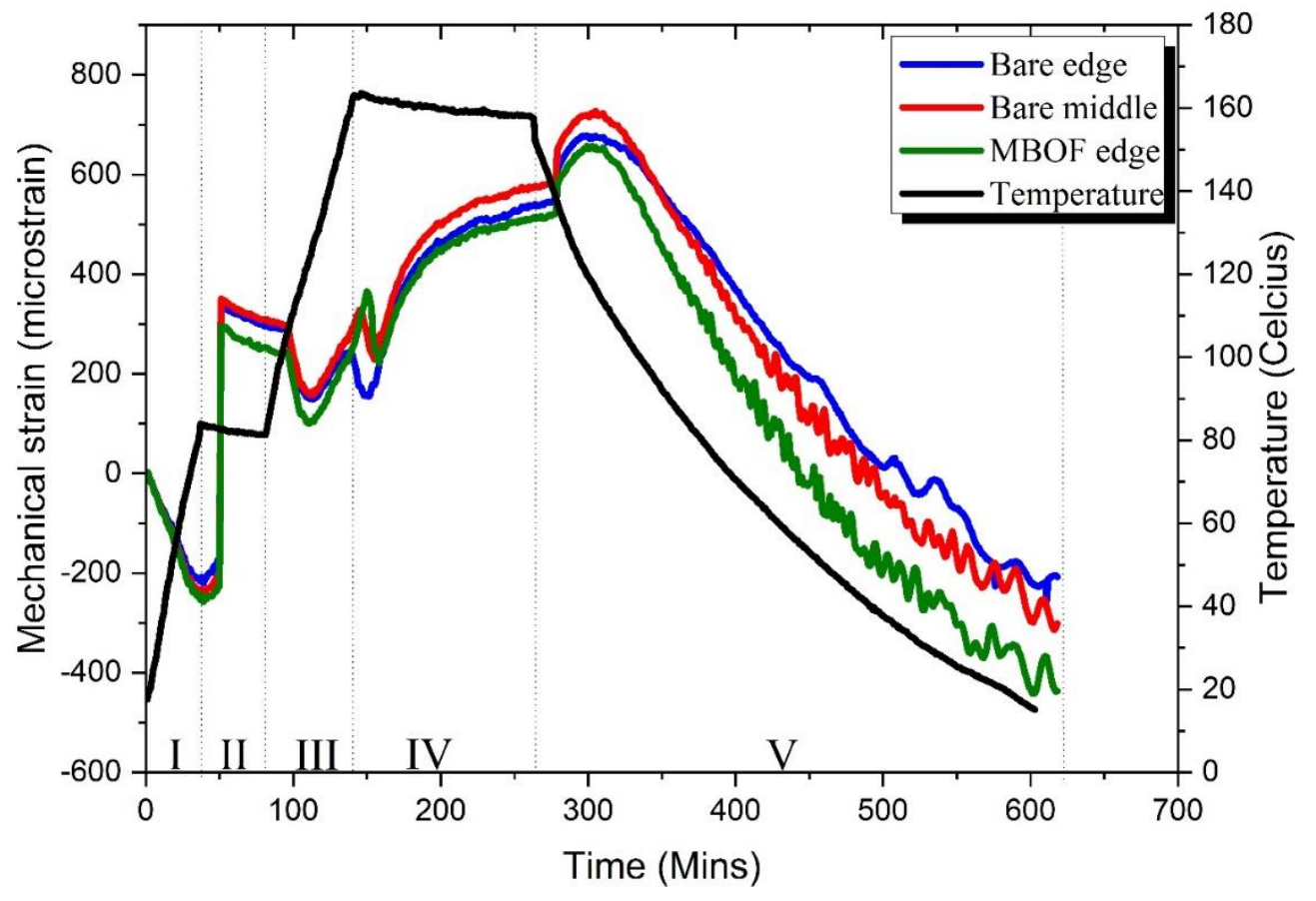

Figure 4 


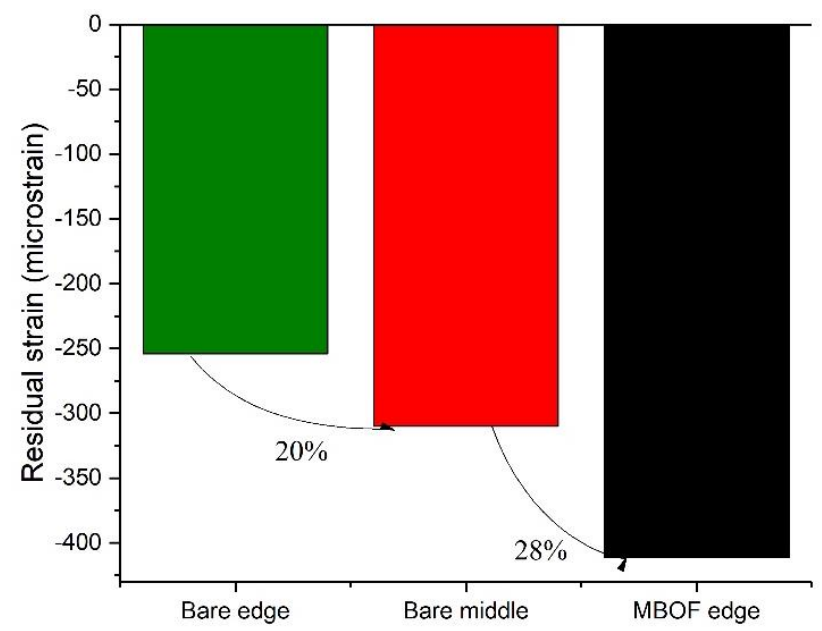

Figure 5 


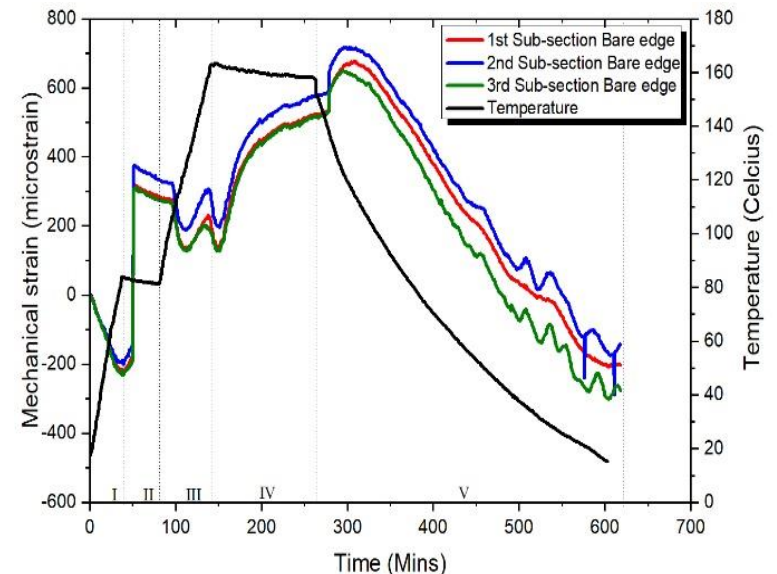

(a)

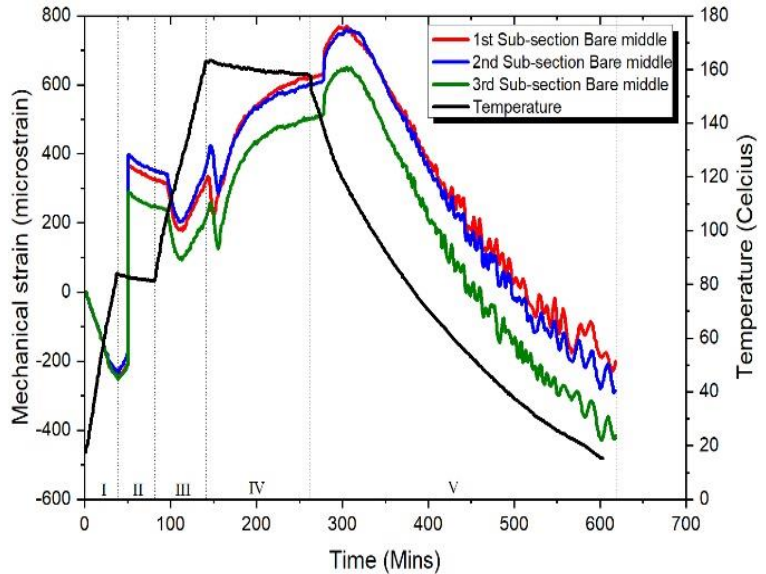

(b)

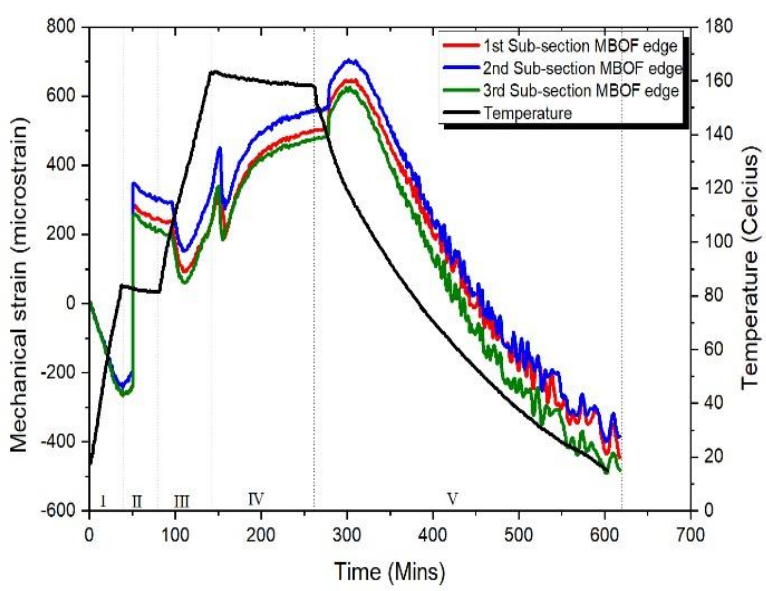

(c)

Figure 6 

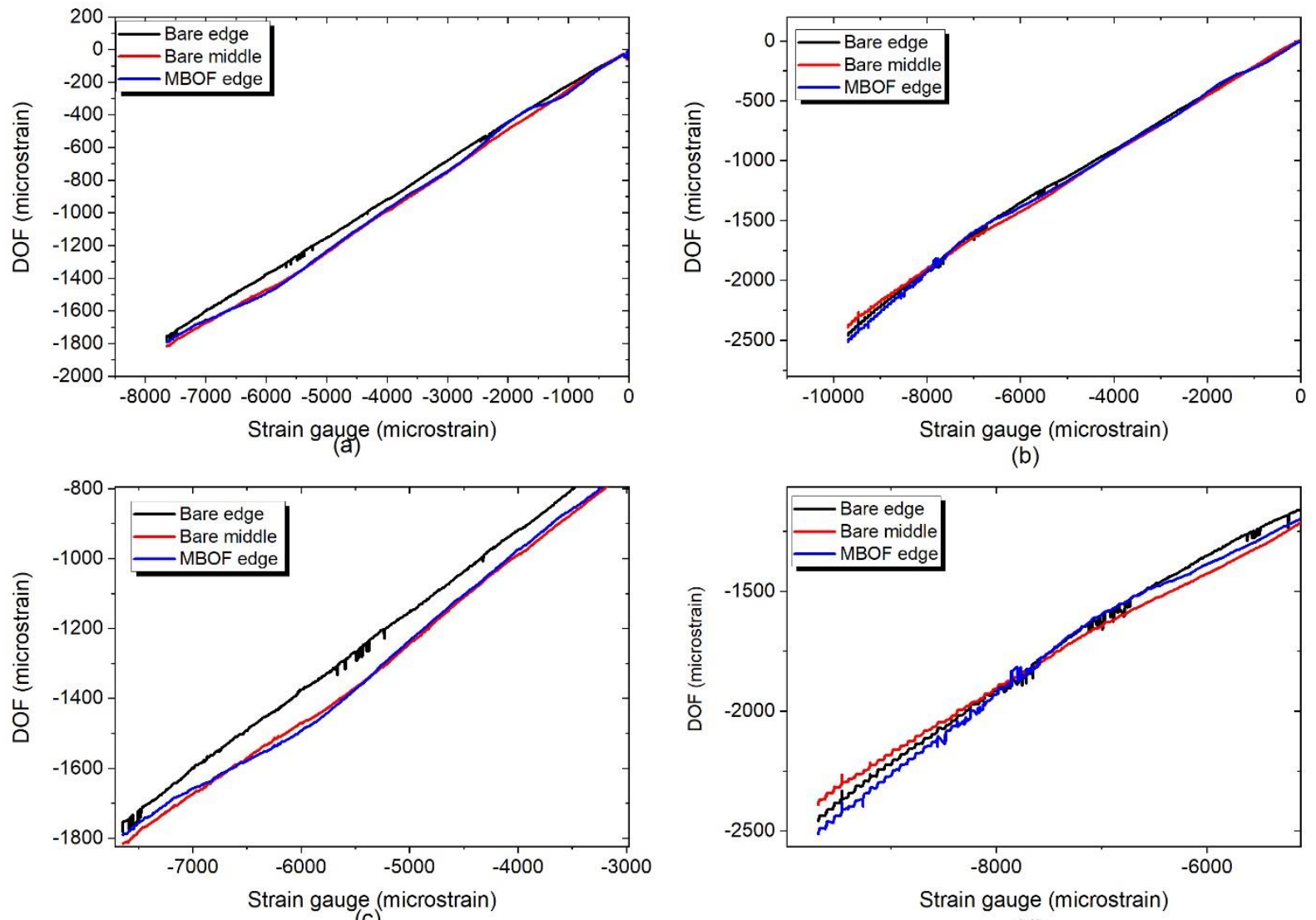

(d)

Figure 7 


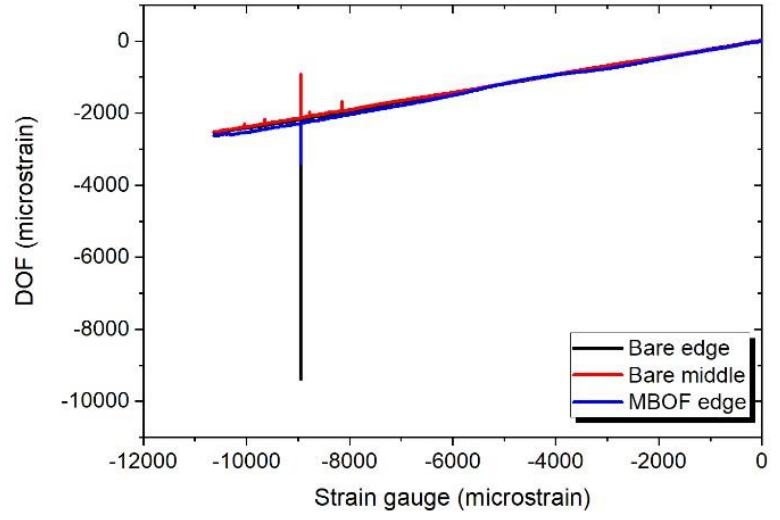

(a)

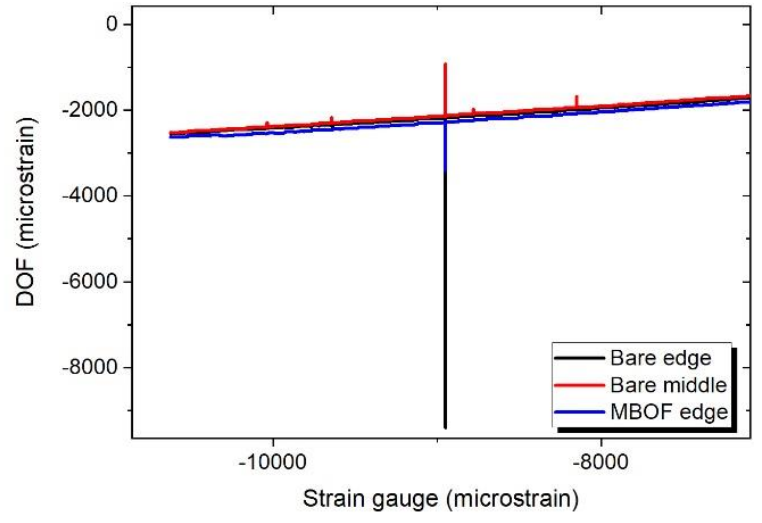

(b)

Figure 8 

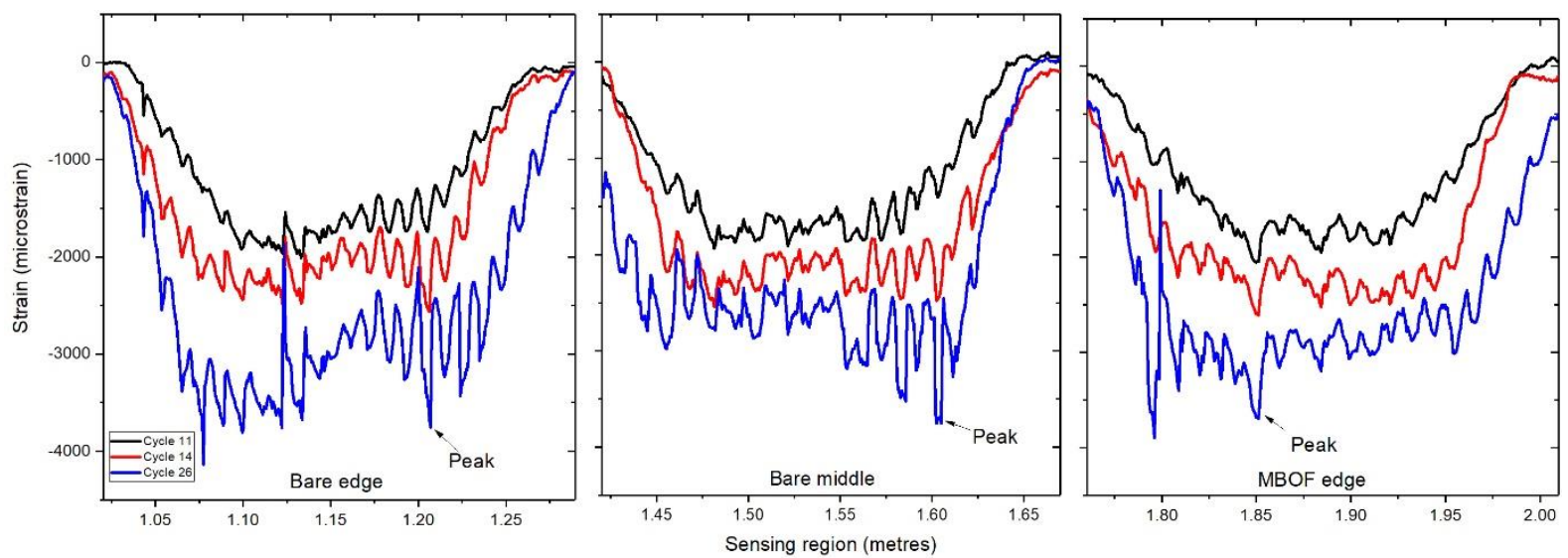

Figure 9 


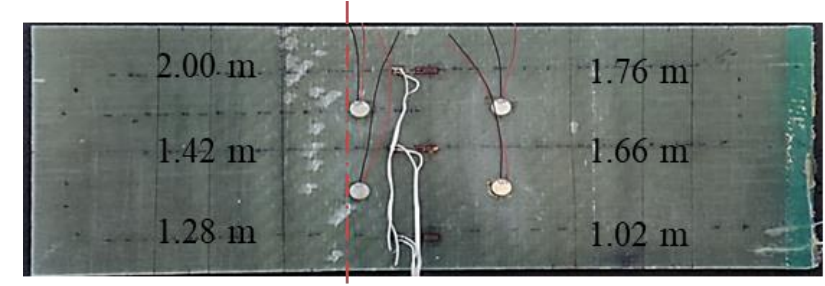

(a)

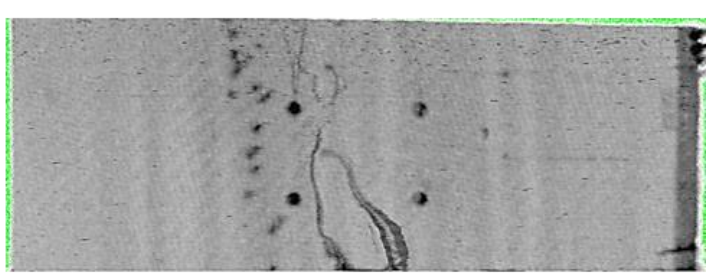

(b)

Figure 10 


\section{List of tables}

Table 1: Residual strain values reported in the literature due to the curing process of composites.

Table 2: Loading cycles of four point bending test

Table 3: Average residual strain in the DOF sub-sections. 
Table 1

Residual strain values reported in the literature due to the curing process of composites.

\begin{tabular}{|c|c|c|c|c|c|c|}
\hline Ref. & Materials & Sensor & Fibre layup & $\begin{array}{c}\text { Manufacturing } \\
\text { method }\end{array}$ & $\begin{array}{l}\text { Residual } \\
\text { strain in } \\
\text { LD }(\mu \varepsilon)\end{array}$ & $\begin{array}{l}\text { Residual } \\
\text { strain in } \\
\mathrm{TD}(\mu \varepsilon)\end{array}$ \\
\hline [1] & CF/Ep & DOF & $\begin{array}{c}\text { Fabric }\{90\} / \text { fabric }_{2}\{90\} / \text { fabric }_{2} \\
\{90\} \text { fabric }\end{array}$ & VARIM & $\begin{array}{c}-405 /- \\
347 /-291\end{array}$ & - \\
\hline$[33]$ & CF/Ep & DOF & {$\left[0_{7} /\{\mathbf{0}\} / 0_{8}\right]$} & Autoclave & -1500 & \\
\hline$[42]$ & GR/Ep & $\begin{array}{l}\text { (FBG/E } \\
\text { FPI) } \\
\text { Hybrid }\end{array}$ & $\begin{array}{c}\left.0_{12} / \mathbf{\{ 0 , 9 0 \}} / 0_{12}\right]_{\mathrm{T}} \\
\left.\left[0_{3} / \mathbf{\{ 0}\right\} / 0_{3} / 90_{6} / \mathbf{9 9 0} / / 90_{6} / 0_{6}\right]_{\mathrm{T}} \\
\left.\text { Fabric }_{8} /\{0,90\} / \text { fabric } 8\right]_{\mathrm{T}}\end{array}$ & Autoclave & $\begin{array}{c}-140 \\
-410 /- \\
470 \\
-210 /- \\
240\end{array}$ & -4000 \\
\hline$[44]$ & CFRP & EFPI & $\begin{array}{c}{\left[0 /\{\mathbf{0}\} / 0_{2} / 90_{4} / 90_{3} /\{\mathbf{9 0}\} / 0_{4}\right]^{\mathrm{ND}}} \\
\left.\left[0 /\{\mathbf{0}\} / 0_{2} / 90_{4} / 90_{3} / \mathbf{\{ 9 0}\right\} / 0_{4}\right]^{(\mathrm{WD})}\end{array}$ & Heat press & $\begin{array}{l}-230^{(\mathrm{ND})} \\
-260^{(\mathrm{WD})}\end{array}$ & $\begin{array}{l}4400^{(\mathrm{ND})} \\
4360^{(\mathrm{WD})}\end{array}$ \\
\hline$[46]$ & GF/EP & FBG & - & Autoclave & -2200 & \\
\hline [47] & GR/EP & $\begin{array}{l}\text { (FBG/E } \\
\text { FPI) } \\
\text { Hybrid }\end{array}$ & $\left.\left.\left[0_{6} / \mathbf{\{ 0}\right\} / 0_{6} / 90_{6} / \mathbf{\{ 9 0}\right\} / 90_{6}\right]_{\mathrm{T}}$ & Autoclave & $\begin{array}{l}-440 \\
-440\end{array}$ & -520 \\
\hline$[48]$ & GR/Ep & FBG & $\begin{array}{c}90 / 0 / 90 / 0 /\{\mathbf{9 0}\} / 0 / 90 / 0- \\
0 / 90 / 0 / 90 / 0 / 90 / 0 / 90]\end{array}$ & Hot mould & - & 1290 \\
\hline [43] & GR/EP & MIDG & UD laminate $\left[0_{16}\right]$ & Autoclave & 0 & -5000 \\
\hline [45] & $\mathrm{CF} / \mathrm{EP}$ & FBG & UD laminate & Autoclave & -4500 & -4500 \\
\hline [49] & GF/EP & FBG & UD laminate & - & $-120 /$ & -280 \\
\hline$[50]$ & GR/EP & FBG & $\begin{array}{l}\text { UD (FBG embedded mid-ply) } \\
\text { UD (FBG embedded surface- } \\
\text { ply) }\end{array}$ & Hot press & $\begin{array}{c}-385 /- \\
453 \\
-20 /-87\end{array}$ & - \\
\hline$[51]$ & CF/EP & FBG & {$\left[0_{5} / 90_{5} / \mathrm{FBG} / 90_{5} / 0_{5}\right]$} & Hydraulic press & -360 & - \\
\hline$[52]$ & GFRP & FBG & $\begin{array}{c}{[(+45 /-45 / 0)\{0\}(0 /-45 /+45)]_{\mathrm{s}}} \\
{[(0 /-45 /+45)(+45 /-45 / 0)\{0\}(0} \\
/-45 /+45)]_{\mathrm{s}} \\
{[(+45 /-45 / 0)(0 /-45 /+45)(+45 /} \\
-45 / 0)\{0\}(0 /-45 /+45)]_{\mathrm{s}}\end{array}$ & VARIM & $\begin{array}{l}-330 \\
-470 \\
-540\end{array}$ & - \\
\hline [53] & CFRP & DOF & $\begin{array}{c}\text { UD laminate } \\
{\left[45^{\circ} / 0^{\circ} / 0^{\circ} /-45^{\circ} / 90^{\circ} / 45^{\circ} / 0^{\circ} / 0^{\circ} \%\right.} \\
\left.-45^{\circ} / 0^{\circ}\right] \mathrm{s}\end{array}$ & VARIM & - & -5000 \\
\hline
\end{tabular}

$\mathrm{CF}=$ Carbon fibre, $\mathrm{GF}=$ Glass fibre Ep= Epoxy, GR= Graphite, $\mathrm{CFRP}=$ Carbon fibre reinforced polymer, UD = Unidirectional, FBG $=$ Fibre bragg grating, DOF $=$ Distributed optical fibre, EFPI $=$ Extrinsic fabry-perot interferometer, MIDG = Moire interometry diffraction grating, $\mathrm{TD}=$ Transverse direction, $\mathrm{LD}=$ Longitudinal direction, $\mathrm{ND}=$ No damage, $\mathrm{WD}=$ With damage, \{\}$=$ Location and relative orientation of the optical fibre sensor. 


\section{Table 2}

Loading cycles of four point bending test

\begin{tabular}{|c|c|}
\hline Loading cycle & Mean compressive strain (SG1 to SG3) $(\mu \varepsilon)$ \\
\hline 1 & $972 \pm 42$ \\
\hline 2 & $1908 \pm 80$ \\
\hline 3 & $2846 \pm 122$ \\
\hline 4 & $3790 \pm 166$ \\
\hline 5 & $4729 \pm 212$ \\
\hline 6 & $5638 \pm 281$ \\
\hline $12-11$ & $7511 \pm 381$ \\
\hline $22-26$ & $9385 \pm 481$ \\
\hline
\end{tabular}


Table 3

Average residual strain in the DOF sub-sections.

\begin{tabular}{|c|c|c|c|c|}
\hline \multirow{2}{*}{ Section of DOF } & \multicolumn{4}{|c|}{ Residual strain $(\boldsymbol{\mu \varepsilon})$} \\
\cline { 2 - 5 } & Full section & Sub-section 1 & Sub-section 2 & Sub-section 3 \\
\hline Bare edge & $-126 \pm 77$ & $-119 \pm 77$ & $-116 \pm 53$ & $-164 \pm 91$ \\
\hline Bare middle & $-154 \pm 90$ & $-109 \pm 60$ & $-144 \pm 77$ & $-239 \pm 110$ \\
\hline MBOF edge & $-239 \pm 124$ & $-237 \pm 115$ & $-218 \pm 108$ & $-291 \pm 129$ \\
\hline
\end{tabular}




\section{Nomenclature}

$\begin{array}{ll}v & \text { mean optical frequency } \\ \lambda & \text { mean wavelength } \\ k_{T} & \text { temperature calibration constant } \\ k_{\varepsilon} & \text { strain calibration constant } \\ \Delta T & \text { change in temperature } \\ \Delta v & \text { spectral shift } \\ \Delta \lambda & \text { change in wavelength } \\ \varepsilon_{m} & \text { mechanical strain } \\ \varepsilon_{T} & \text { total strain } \\ \varepsilon_{t} & \text { thermal strain } \\ p_{11}, p_{12} & \text { strain-optic tensor } \\ \alpha & \text { coefficient of thermal expansion (CTE) } \\ \xi & \text { thermos-optic coefficient } \\ \mu & \text { Poisson's ratio }\end{array}$

